\title{
Managing the Mental Health of Persons with Disabilities amid the COVID-19 Pandemic in the Philippines: Specific Factors and Key Actions
}

\author{
Erwin E. Rotas ${ }^{1 *}$, Michael Cahapay ${ }^{2}$
}

${ }^{1}$ Teacher I, Department of Education, PHILIPPINES

${ }^{2}$ College of Education, Mindanao State University, General Santos City, Fatima, PHILIPPINES

*Corresponding Author: erwinemperadorotas@gmail.com

Citation: Rotas, E. E. and Cahapay, M. (2021). Managing the Mental Health of Persons with Disabilities amid the COVID-19 Pandemic in the Philippines: Specific Factors and Key Actions. European Journal of Environment and Public Health, 5(2), em0077. https://doi.org/10.21601/ejeph/10954

ARTICLE INFO

Received: 1 Dec. 2020

Accepted: 13 Jan. 2021

\begin{abstract}
This paper discusses the specific factors and key actions in managing the mental health of persons with disabilities (PWDs) amid Coronavirus Disease 2019 (COVID-19) pandemic in the Philippines. It is a short report that discusses the continuous record of knowledge related to the management of the mental health of PWDs amid the COVID-19 crisis specifically in the Philippines. The specific factors such as inadequate information, negative social perceptions, and inaccessible medical services are found to exacerbate the situation. The key actions such as policy review, stakeholder participation, continued support, and inclusive research are cogently identified. This paper provides a contribution in understanding more about the mental health of PWDs amid the COVID-19 crisis in a developing country. With the PWDs in mind, it is suggested to reconsider current guidelines, involve stakeholders in multisectoral responses, sustain financial subsidy, and conduct inclusive research and census.
\end{abstract}

Keywords: mental health, persons with disabilities, COVID-19 pandemic, Philippines

\section{INTRODUCTION}

The COVID-19 is overwhelmingly distressing people from all walks of life. According to Fegert et al. (2020), the economic shutdown and social isolation have most likely resulted in a complete transformation of the psychosocial environment. They further claimed that the current crisis has presented a challenging time and huge potential to impact the mental health of people. Studies on the mental impact of mass disturbances such as natural disasters and disease outbreaks indicate that the current crisis may particularly harm the mental health of marginalized populations (e.g., Goldmann and Galea, 2014). These marginalized populations include vulnerable segments like the PWDs.

Acknowledging the importance of mental health, the United Nations (2020) has called for the need for actions to safeguard mental health. It pointed out that particular population groups such as PWDs show a high level of psychological concerns related to the COVID-19 pandemic. For one, it urged that "mental health and social care for people with severe mental health conditions and psychosocial disabilities must be part of the definition of essential services in all countries” (p. 15). The World Health Organization (2020) likewise recognized the greater risk of PWDs of contracting the COVID-19 infection. It recommended disability considerations that include providing general health care and psychosocial support.

The overall condition of the PWDs in the Philippines and the different services intended for them are a matter that needs further improvement. For example, most PWDs receive government benefits in the form of transfer income but employment opportunities are still a challenge (Mina, 2013). Moreover, there are just a few institutional care facilities for PWDs in the country and most of the PWDs live in homes that they or their families own (Reyes et al., 2011). There are also various national provisions that cover the medical needs of PWDs but facilities are plagued by issues on accessibility (Commission on Human Rights, 2018). On the other hand, most children with disabilities are mainstreamed in and separated from regular classrooms on a case to case basis (Alcober, 2017) but educational services observably need more development.

When it comes to mental health, there are no national data on the extent of mental health among the citizens and PWDs of the Philippines especially in the advent of the COVID-19 pandemic. However, there are extant indicators that may suggest. For example, according to the Philippine Statistics 
Authority (2010), there are 1.4 million Filipinos with disabilities who have a mental disorder. There are current national efforts with a focus on improving the mental health of the people as a part of the COVID-19 Humanitarian Response Plan but they focus only on targeted beneficiaries in some regions (Philippines Humanitarian Country Team, 2020).

Some initial efforts in other aspects have been placed to assist PWDs amid the COVID-19 crisis. For example, PWDs are covered in the provisions of the recent Republic Act No. 11469 which mandates the distribution of cash assistance to vulnerable people in light of the COVID-19 crisis. Moreover, children with disabilities are included in the collaboration between Save the Children Philippines and the Department of Education in their response to implement adaptive learning in the new normal period (Office for the Coordination of Humanitarian Affairs, 2020). However, these efforts may just present short-term mechanisms as a response to the current COVID-19 crisis. There is a further need to generate long-term key actions that will usher the PWDs toward an inclusive new normal.

A review of the key factors that underlie the situation of PWDs before the pandemic in a developing country like the Philippines is important. Such prior information will reveal an approximate representation of the conditions that may further increase the vulnerability of PWDs in the present. If this discussion is presented, it will lead to a proposal of possible actions to manage the PWDs amid the current COVID-19 crisis. These actions will shape the other focus of this paper towards the end.

Thus, the purpose of this short report is to discuss the specific factors and key actions in managing the mental health of PWDs amid the COVID-19 pandemic in the Philippines.

\section{SPECIFIC FACTORS THAT UNDERLIE THE VULNERABILITY OF PWDS}

This paper has an initial purpose to review the specific factors that reveal the propensity of PWDs toward vulnerability amid the COVID-19 crisis. There are certain factors that are often provided attention in studies on the vulnerable segments of society. Based on the analysis of themes (e.g., Cahapay, 2020 on senior citizens), these factors are contextualized in this study as inadequate information on the types of disability, negative social perceptions toward PWDs, and inaccessible medical services particular to PWDs.

\section{Inadequate Information on the Types of Disability}

Based on the 2010 population census, out of the 92.1 million household population in the country, 1.44 million persons or 1.57 percent had disability (Philippine Statistics Authority, 2010). The census also included their distribution by age and sex across regions. However, the exact number of PWDs by particular types of disability such as intellectual disability and developmental disability is unknown. This problem springs from another problem which is the perennial inadequacy of access to diagnosis services (Jaucian, 2020). Most of the surveys conducted on disability are not a census but sample surveys based on not highly reliable sources (Mori et al., 2009). Hence, the identification of the types of disability is still a major problem in the country. A particular type of disability requires different responses. The current inadequate information about the types of disability of PWDs, however, may translate to difficulties in addressing the mental health issues of this vulnerable group amid the current crisis. As such, the formulation of relevant, appropriate, and responsive mental health programs may pose a great challenge particularly during this time of restrictions.

\section{Negative Social Perceptions toward PWDs}

Despite numerous policies such as Executive Order No. 385 and Executive Order No. 261 that promote social awareness for PWDs in the country, stereotypes are still prevalent. For example, in a recent 2019 research, results revealed that there is a general hesitancy on the part of human resource officers, managers, and supervisors to employ PWDs. Some employers still see disabilities as obstructions for productive occupations (Alson et al., 2019). As mentioned earlier, PWDs receive financial aid through transfer income. However, they are still way behind suitable employment opportunities due to discriminatory practices (Mina, 2013). Considering the present crisis in the country, these stereotypes might be magnified in the selective guidelines, reproducing bias against PWDs. The United Nations Human Rights (2020) cited as an example the triage guidelines for the allocation of inadequate resources with exclusion criteria based on certain types of impairment. This bias against PWDs in the Philippines has been reported in other spheres of community life amid the COVID-19 crisis. For instance, there are news reports about the refusal of insurance contract application (de Vera, 2020) as well as employment on the ground of disability (Espinosa, 2020).

\section{Inaccessible Health Services Particular to PWDs}

The health welfare of the PWDs in the country is covered in the laws such as Republic Act No. 11228, which mandates the development of exclusive packages for PWDs addressing specific health and development needs. Another law is the Republic Act No. 7277 on the provision of auxiliary aids and services, and rehabilitation, and the Republic Act No. 10754 on the discounts on essential medical services such as medicine and laboratory tests. However, the Commission on Human Rights (2018) noted that rural medical facilities are still not accessible or have inadequate particular supplies. It further pointed out that the marginalized sector that includes the PWDs can avail of the health services through sponsored programs, but they still need to apply or be identified for this sponsorship. This unfavorable situation reveals inequality in health access for PWDs which may further worsen amid the ongoing health crisis.

\section{KEY ACTIONS TO MANAGE THE MENTAL HEALTH OF PWDs}

This report is shaped by another focus on providing key actions to manage the mental health of PWDs amid the COVID-19 crisis. The following key actions are cogently based on the specific factors initially discussed in this paper. These 
key actions are also based on evidence of good practices in other countries with similar situations.

(1) Since existing negative stereotypes may highly reproduce biases against PWDs in the different aspects of life amid the COVID-19 pandemic, possible biases preventing access based on disability especially on the level of care, support, and employment should be monitored. There is a need for the government to carefully review guidelines and issue orders to ensure that PWDs get equal services and privileges during the COVID-19 crisis. This move is evident in terms of care in the United States where the Department of Health and Human Services Office of Civil Rights has issued a bulletin warning to medical service providers against denial of PWDs from COVID-19 care (Pulrang, 2020).

(2) The different stakeholders are strongly encouraged to take key action by consulting with representative organizations to frame multisectoral mental health responses for PWDs. These responses may include human rights groups, education sector, health department, disability organizations, and private stakeholders. For example, educational institutions should conduct webinars for families of PWDs and the PWDs themselves to discuss coping strategies to stand the psychosocial pressures brought by the crisis. On the other hand, the health care service providers should establish or increase their telehealth system in the country to include especially the PWDs in the remote areas. This intervention has been implemented in Nigeria where INTERSOS organization provides psychosocial support services. It includes group counseling and assessment of community needs to monitor and address gaps in the mental health among vulnerable groups (Adesina et al., 2020).

(3) Another key action to the highest attainable standard of mental health is sustainability. Thus, to ensure the wellbeing of PWDs amid and beyond the COVID-19 crisis, there should be continuous support on subsidy for existing policies on national mental health responses, improvement of social services especially at the community level, protection of their rights by monitoring equal access to such services, and promotion of inclusive education in the new normal period. Such practice is reflected in Sri Lanka where improvements in providing mental health services are sustained. This action was made possible because of the pledged support of local and national health authorities even beyond the program period (Budosan et al., 2020).

(4) Several scholarly works have been published to assess the mental health of Filipinos amid the pandemic (e.g., Cahapay, 2020 on senior citizens; Baloran, 2020 on college students; Delos Santos \& Labrague on working nurses). An inclusive narrative assessing the mental health of the PWDs is also a significant key action in these times. An awareness of the risks may lead to better responses and draw attention to some extant evidence of good practices that are already being undertaken. This effort was done in several countries like China where mental health risks of COVID-19 in vulnerable groups were assessed to identify mitigating factors and apply appropriate psychological interventions (e.g. Zhu et al., 2020 on mentally ill).

(5) As part also of inclusive research, there is a need to include in the national census the particular type of disabilities of PWDs especially those with intellectual and developmental disabilities. This key action will assist in mapping out PWDs by type of disabilities and design interventions that are relevant, appropriate, and responsive. It should be further noted that an enabling mechanism to attain this key action is the expansion of diagnosis services, so that accurate physiological, intellectual, and developmental status of PWDs can be sought.

\section{CONCLUSION}

A closer look at the specific factors can lead to the formulation of key actions to manage the mental health of PWDs amid the current COVID-19 crisis. This short report discussed the specific factors and key actions in managing the mental health of PWDs amid the COVID-19 pandemic in a developing country of the Philippines. This paper presented the specific factors like inadequate information on the types of disability, negative social perceptions toward PWDs, and inaccessible medical services particular to PWDs. These factors most likely worsen the present mental health of PWDs, especially amid the COVID-19 crisis. Based on these specific factors, key actions such as policy review, stakeholder participation, continued support, and inclusive research are offered. These actions indicate the need to reconsider current guidelines in designing intervention programs for PWDs, involve stakeholders in multisectoral responses for PWDs, sustain the subsidy to support PWDs, and include the PWDs in the present mental health assessment and national census. Set in a developing country, this work provides significance to readers across the globe to know more about the mental condition of PWDs amid the COVID-19 pandemic.

Author contributions: All co-authors have involved in all stages of this study while preparing the final version. They all agree with the results and conclusions.

Funding: No external funding is received for this article.

Declaration of interest: The authors confirm that there are no relevant financial or non-financial competing interests to report for this paper.

Ethics approval and consent to participate: Not applicable.

Availability of data and materials: All data generated or analyzed during this study are available for sharing when appropriate request is directed to corresponding author.

\section{REFERENCES}

Adesina, M. A., Oladele, R. I. and Olufadewa, I. I. (2020). Mental health and psychosocial support in conflicting Nigeria. Yenagoa Medical Journal, 2(4), 15-23. https://www.researchgate.net/publication/344168948 
Alcober, N. (2017, February 26). Over 600 schools cater to children with special needs -DepEd. Available at: https://www.manilatimes.net/2017/02/26/news/topstories/600-schools-cater-children-special-needsdeped/314217/

Alson, J. N., Espela, C. S. and Urbina, M. A. C. O. (2019). Factors affecting employability of persons with disabilities. International Journal of Multidisciplinary Research and Publications, 1(9), 1-5. Retrieved from http://ijmrap.com/ wp-content/uploads/2019/02/IJMRAP-V1N8P271Y19.pdf

Baloran, E. T. (2020). Knowledge, attitudes, anxiety, and coping strategies of students during COVID-19 pandemic. Journal of Loss and Trauma, 25(8), 635-642. https://doi.org/10.1080/15325024.2020.1769300

Budosan, B., Mahoney, J., Dorego, W. C., Aziz, S. \& Ratnasabapathipillai, K. (2020). Three models of scaling up mental healthcare post-disaster: common challenges. Intervention, 18(1), 18-27. https://www.researchgate.net/ publication/344168948

Cahapay, M. B. (2020). Senior citizens during COVID-19 crisis in the Philippines: Enabling laws, current issues, and shared efforts. Research on Ageing and Social Policy, 9(1), 125. https://doi.org/10.447/rasp.2021.6066

Commission on Human Rights (2018). Response to the questionnaire right of persons with disabilities to the highest attainable standard of health. Available at: www.ohchr.org/ Documents/Issues/ESCR/SDG/NHRI_Philippines.docx

de Vera, B. O. (2020, August 28). IC chief warns insurers: Discrimination vs PWDs illegal. Philippine Daily Inquirer. Available at: https://business.inquirer.net/306092/icchief-warns-insurers-discrimination-vs-pwds-illegal

Delos Santos, J. A. and Labrague, L. (2020). Impact of COVID19 on the psychological well-being and turnover intentions of frontline nurses in the community: A cross-sectional study in the Philippines. medRxiv. https://doi.org/10.1101/2020.08.05.20167411

Espinosa, M. C. L. (2020, July 22). PWDs' livelihood affected by COVID-19 pandemic. Philippine Information Agency. Available at: https://pia.gov.ph/news/articles/1048292

Executive Order No. 261 (1995). Available at: https://www.officialgazette.gov.ph/1995/07/17/executiveorder-no-261-s-1995/

Executive Order No. 385 (1996). Available at: https://www.ncda.gov.ph/disability-laws/executiveorders/executive-order-no-385/

Fegert, J. M., Vitiello, B., Plener, P. L. and Clemens, V. (2020). Challenges and burden of the Coronavirus 2019 (COVID19) pandemic for child and adolescent mental health: A narrative review to highlight clinical and research needs in the acute phase and the long return to normality. Child and Adolescent Psychiatry and Mental Health, 14(1), 1-11. https://doi.org/10.1186/s13034-020-00329-3

Goldmann, E. and Galea, S. (2014). Mental health consequences of disasters. Annual Review of Public Health, 35, 169-183 https://doi.org/10.1146/annurev-publhealth032013-182435
Jaucian, D. (2020, March 03). Breaking the stigma on Filipino children with disabilities. CNN Philippines. Retrieved from https://cnnphilippines.com/life/culture/2017/03/03/lottasylwander-interview-unicef.html

Mina, C. D. (2013). Employment of persons with disabilities (PWDs) in the Philippines: The case of Metro Manila and Rosario, Batangas. Philippine Institute for Development Studies. Retrieved from https://pidswebs.pids.gov.ph/ ris/dps/pidsdps1313.pdf

Mori, S., Reyes, S. and Yamagata, T. (2009). Poverty reduction for the disabled in the Philippines. Institute of Developing Economies. Available at: https://disability-studies.leeds.ac. uk/wp-content/uploads/sites/40/library/mori-JRP151Philippine-PWD-Livelihood.pdf

Office for the Coordination of Humanitarian Affairs (2020, May 16). Save the Children Philippines supports DepEd adaptive learning methods for children, youth amid COVID-19 pandemic. Available at: https://reliefweb.int/report/ philippines/save-children-philippines-supports-depedadaptive-learning-methods-children-youth

Philippine Statistics Authority (2010). Persons with disability in the Philippines: Results from the 2010 Census. Available at: https://psa.gov.ph/content/persons-disabilityphilippines-results-2010-census

Philippines Humanitarian Country Team (2020, August 4). Philippines COVID-19 Humanitarian Response Plan (August 2020 Revision). Available at: https://reliefweb.int/ report/philippines/philippines-covid-19-humanitarianresponse-plan-august-2020-revision

Pulrang, A. (2020, April 14). The disability community fights deadly discrimination amid the COVID-19 pandemic. Forbes. Available at: https://www.forbes.com/sites/ andrewpulrang/2020/04/14/the-disability-communityfights-deadly-discrimination-amid-the-covid-19pandemic/\#37c64943309c

Republic Act No. 10754 (2016). IRR of RA 10754 -An Act expanding the benefits and privileges of Persons With Disability (PWD). Available at: https://www.ncda.gov.ph/ disability-laws/implementing-rules-and-regulationsirr/irr-of-ra-10754-an-act-expanding-the-benefits-andprivileges-of-persons-with-disability-pwd/

Republic Act No. 11228 (2018). RA 11228 - An Act Providing for the Mandatory Philhealth Coverage for All Persons With Disability (PWDs), Amending for the Purpose Republic Act No. 7277, As Amended, Otherwise Known as the "Magna Carta for Persons With Disability". Available at: https://www.ncda.gov.ph/disability-laws/republicacts/republic-act-no-11228/

Republic Act No. 11469 (2020). Implementing rules and regulations of Section 4(aa) of Republic Act No. 11469, Otherwise known as the "Bayanihan to Heal As One Act". Available at: https://www.officialgazette.gov.ph/2020/04/ 01/implementing-rules-and-regulations-of-section-4aaof-republic-act-no-11469-otherwise-known-as-thebayanihan-to-heal-as-one-act/ 
Republic Act No. 7277 (1992). RA 7277 - An Act providing for the rehabilitation, self-development and self-reliance of disabled person and their integration into the mainstream of society and for other purposes. Available at: https://www.ncda.gov.ph/disability-laws/republicacts/republic-act-7277/

Reyes, C. M., Tabuga, A. D., Mina, C. D., Asis, R. D. and Datu, M. B. G. (2011). Persons with Disability (PWD) in rural Philippines: Results from the 2010 field survey in Rosario, Batangas. Philippine Institute for Development Studies. Available at: https://dirp3.pids.gov.ph/ris/dps/pidsdps 1106.pdf

United Nations Human Rights (2020). COVID-19 and the rights of persons with disabilities. Available at: https://www.ohchr. org/Documents/Issues/Disability/COVID-19_and_The Rights_of_Persons_with_Disabilities.pdf
United Nations. (2020). COVID-19 and the need for action on mental health. Available at: https:/unsdg.un.org/sites/ default/files/2020-05/UN-Policy-Brief-COVID-19-andmental-health.pdf

World Health Organization (2020). Disability considerations during the COVID-19 outbreak. Author. Available at: https://www.who.int/docs/default-source/inaugural-whopartners-forum/english-covid-19-disabilitybriefing.pdf?sfvrsn=8a1aa727_1\&download=true

Zhu, Y., Chen, L., Ji, H., Xi, M., Fang Y. and Li Y (2020). The risk and prevention of novel coronavirus pneumonia infections among inpatients in psychiatric hospitals. Neurosci. Bull, 36(3), 299-302. https://doi.org/10.1007/s12264-02000476-9 